\title{
Stress Psychology and Self - adjustment of Teachers in Higher Vocational Colleges
}

\author{
Author unit: Tianjin Maritime College
}

Author's name: Li Wu

postal code: 300350

Key words: vocational college teachers; stress psychology;

\begin{abstract}
In recent years, higher vocational education has shown an unprecedented momentum of development. The number of students in vocational colleges has continued to grow. The scale of higher vocational education has accounted for half of the ordinary higher education. Facing the rapid development and great changes into higher vocational education, teachers in higher vocational colleges face enormous teaching and research pressure, and many teachers have different psychological stress. This paper analyzes the factors that lead to teachers 'psychological stress and explores the specific methods of self - adjustment with the situation of teachers ' work in higher vocational colleges.
\end{abstract} I

\section{Introduction}

Stress is a very complex psychological phenomenon, psychological research shows that the appropriate state of stress can help teachers in the teaching process to maintain a good state, so as to ensure a better teaching effect. But if the teacher in such a long-term state, physical and mental health will be greatly affected. The research shows that the students in vocational colleges are obviously superior to undergraduates in terms of practical ability and so on, but there are obvious problems of theoretical study and academic research, and many students still have poor self-control force, lack of concentration, interest and other issues. Therefore, teachers in vocational colleges in the classroom usually need to spend more energy to manage the students, if the management of the law, it led to the vocational college teachers in the work processes prone to a long time of stress. Obviously, this state on the one hand will have an impact on the mental health of teachers, on the other hand will lead to a straight line of actual teaching effect. In the study of stress-related theories, the study of stress in the early psychology is mainly aimed at stress stimulation and physiological response. Modern stress psychology is more focused on the multi-factor system theory. In this system, the discussion of stress should be discussed from three aspects: stressors, intermediate variables, and stress response. This paper will put forward practical and feasible self - adjustment program on the basis of analyzing the causes of teachers ' psychological stress in vocational colleges.

\section{Analysis of Stress Source}

The factors that lead to the psychological stress of teachers in vocational colleges are as follows:

First of all, the teaching environment is one of the main factors that lead to the psychological stress of teachers in vocational colleges. Environmental lighting, air pollution, excessive noise and other conditions are likely to lead to teachers have psychological stress.

Second, the burden of work is also one of the key factors that lead teachers to generate psychological stress. According to the survey, some vocational colleges teachers take 400-500 hours per semester on heavy teaching work tasks, but also to complete the scientific research, training, business practice and many other jobs, the workload is heavy. If the adjustment is not good, long-term fatigue of the work will make teachers in the psychological have a certain sense of boredom, and then produce stress psychology. 
Finally, interpersonal relationships may also be one of the stressors of teachers in higher vocational colleges. In the process of getting along with the upper and lower levels or colleagues, teachers are likely to feel the pressure of the emergence of various contradictions, then, teachers are likely to enter the state of stress and affect the classroom teaching effect.

After the sample survey, we have classified the higher vocational college teachers psychological status, from the status quo, we can divide the teacher stress into the following categories:

First, the stress caused by frustration.

The changing training needs and teaching reform of higher vocational education require that teachers in higher vocational colleges must be able to quickly add new knowledge and master new teaching skills so that the teaching can achieve better teaching effect. However, for those teachers who are accustomed to classroom teaching in higher vocational colleges, teachers are likely to be able to follow the fast pace of teaching reform. When the school asks teachers to reform the teaching mode or learn new teaching methods, teachers are likely to need a period of time to adapt, in such a process, vocational teachers will naturally feel the pressure in the teaching process that is easy to produce a sense of frustration, and then produce stress psychology.

Second, the stress caused by the conflict.

As mentioned earlier, compared to students in undergraduate institutions, vocational college teachers need to spend more energy on the management of students. In the actual classroom, teachers are likely to work because of the development of work and students in conflict, then, the contradictions of the stimulus and nervousness are likely to lead to teachers into the state of stress.

\section{Self-adjustment Method}

\subsection{Problem Solving Method}

As we mentioned above, we have already mentioned that the emergence of teachers ' psychological stress in vocational colleges must have some reasons. Then we want to make self-adjustment and find out the causes of stress and solve these problems. Then the teacher will naturally be able to quickly out of the stress state. For example, teachers should communicate and communicate with other colleagues in a timely manner if they feel stress and stress in the course of teaching reform or new teaching skills, and learn from their colleagues with rich experience. It's a good way to ensure that they as soon as possible to adapt to the new teaching model and teaching methods, and from the state of stress out. On the other hand, the way to face the problem may not be the best choice. For example, when the teacher and student disputes, the students speak out to the teacher, then the most direct solution is to face the students to fight back, but it is clear that this approach is contrary to the professionalism of teachers. In the context of this situation, teachers should first consider whether their actions are in line with professional or legal provisions when choosing this method for self-adjustment [1].

\subsection{Emotional Adjustment Method}

Compared with the problem-solving method, emotional adjustment method is a more indirect method [2]. In the process of applying this method to self-adjustment, we do not need to do any treatment of the stress source, but through the adjustment of their own mentality and behavior to achieve the purpose of out of stress. Under normal circumstances, this method is mainly applied to the stress source can not change the situation [3]. When teachers in higher vocational colleges encounter new challenges to the teaching process, teachers can not refuse such a change, we can only through the emotional adjustment method as soon as possible to encourage themselves to accept such a situation and meet such new challenges. In this process, the teacher can put his attention on the fun of the teaching process, rather than the need to achieve the pressure of the target. Through this emotional transformation, vocational college teachers must be able to meet the challenges in the process of achieving good results. It is worth not that this method can not solve all the stress state, when the stress source can change, the emotional adjustment method plays a very small role. On the other hand, teachers in vocational colleges are likely to adjust their emotions by 
means of smoking, alcohol or drugs without the guidance of professionals. From a clinical psychology, this approach is not only about stress the state of regulation can not achieve a positive effect, but will be on the mental health of teachers in vocational colleges have a more serious impact, which is in the process of self-adjustment that needs to be avoided .

\subsection{Humor Adjustment Method}

For psychology, optimistic, positive and progressive quality will be able to avoid a large degree of psychological stress and other mental illness. For teachers in vocational colleges, in the process of self-adjustment, teachers can ease the tension, anxiety and other emotions through the form of humor. in the process of returning visits to people who had suffered a disaster, we found that nearly $40 \%$ of the population was able to use their humor to motivate themselves to face the disaster. In the follow-up period of long follow-up process, this part of the crowd can be faster from the trauma out of the psychological. For example, when a dispute arises out of a teacher and a colleague in a vocational college, we can resolve it in a humorous way, and not only the relationship between the teacher and the colleague is alleviated, but also because of this situation and the resulting pressure.

\subsection{Professional Help}

Most of the vocational colleges are set up in the relevant psychological counseling room, when the teacher has negative emotions, you can timely seek help from professionals to avoid the psychological stress through the way. In this process, teachers can talk to professionals about their work or life problems encountered, and through professional guidance to learn to face these issues, to express the negative emotions, to further increase the psychological problems. Under normal circumstances, when the psychological problems arise, the timely help to professionals is the most effective and most convenient way, but some teachers because of the psychological discipline do not understand, there is prejudice or fear of psychological counseling, for such problems institutions can regularly carry out some psychological lectures for teachers to ensure that teachers in the understanding of psychology at the same time can be better in the face of psychological stress when doing self-debugging.

\section{Conclusion:}

In summary, from the actual teaching process of teachers in higher vocational colleges, this part of the teacher's psychological causes of stress may be related to a number of factors. On the basis of this, this paper puts forward some methods such as problem solving method, emotion adjustment method and humor adjustment method to analyze the specific scheme of self-adjustment of this part of teachers. In general, when teachers are in a state of stress for a long time, we should seek help from professionals in a timely manner and use appropriate adaptation methods to get out of the state as soon as possible so that teachers can ensure physical and mental health .

\section{References:}

[1] Zheng Kangsheng. On teachers' stress psychology and self-adjustment [J]. Education and occupation, 2016 (20).

[2] Ma Min, Wang Bing-yi.Study on Self-adjustment Method and Effect of Teachers' Psychological Pressure in Higher Vocational Colleges [J]. Journal of Mudanjiang Education College, 2015 (6).

[3] Chen Zhi-kun, Liang Jun-hong.New upgraded vocational school teachers mental health self-adjustment strategy practice research [J]. Science and Technology Information, 2015 (3). 